\title{
Corneal Kaposi Sarcoma
}

National Cancer Institute

\section{Source}

National Cancer Institute. Corneal Kaposi Sarcoma. NCI Thesaurus. Code C4579.

A Kaposi sarcoma arising from the cornea. 